\title{
Dous novos lotes de documentación no Arquivo da Real Academia Galega, relacionados con Pardo Bazán
}

\author{
Mercedes Fernández-Couto Tella \\ (Arquivo da Real Academia Galega) \\ arquivo@cademia.gal
}

(recibido maio/2016, revisado xuño/2016)

RESUMO: Breve descrición de correspondencia de Emilia Pardo Bazán e de Amalia de la Rúa.

PALABRAS CLAVE: Emilia Pardo Bazán, José Alguero Penedo, Ramón Platas, Santiago de la Iglesia, Emilio Mã de Torres, Concepción Arenal, Pazo de Meirás.

ABSTRACT: Short brief about correspondence of Emilia Pardo Bazán and Amalia de la Rúa.

KEY WORDS: Emilia Pardo Bazán, José Alguero Penedo, Ramón Platas, Santiago de la Iglesia, Emilio Ma de Torres, Concepción Arenal, Pazo de Meirás.

A proximidade e o achegamento que o Arquivo da RAG mantén cos investigadores fai que se creen sinerxías favorables aos fondos. Así, Isabel Burdiel, pardobazaniana da Universitat de València, infórmanos en xuño de 2015 da venda dun lote de postais autógrafas de Emilia Pardo Bazán por parte dunha librería de vello. Ela mesma refire o posible interese destes documentos pola intimidade do contido. Efectivamente, tanto a Comisión Executiva como os académicos pardobazanianos dan o visto e prace á operación de compra e, deste xeito, ingresa o conxunto unha semana máis tarde.

O lote tal como o describía o vendedor estaba formado por:

655.- Pardo Bazán, Emilia (Condesa). -MANUSCRITOS ORIGINALES. (15 PIEZAS).- Manuscritos.- Todos los escritos dirigidos al mismo destinatario ("Mi querido amigo", "Mi querido notario-artista-romántico", "Amigo artista", "Mi joven amigo".) de índole personal y denotando cierta intimidad, fechadas entre 1901 y 1914. El lote se compone de nueve tarjetas postales circuladas, una de ellas con su fotografía de perfil. Una tarjeta de visita invitando a comer ("Es en Meirás, no en Madrid! Cuidado!"). Dos tarjetones escritos por ambas caras, uno de ellos con la corona condal plateada. Un billete alargado (24×9) escrito a una cara ("Mi querido amigo: ahí envío a V. ese documento, que le ruego conserve hasta el día en que deba V. mostrarlo...") Dos cuartillas orladas de luto, escritas por ambas caras. (“Orden terminante: se trae V. sin réplica ni remilgos esas postales. ¿Quién es usted para decidir si sirven o no sirven? Hablaremos. ¡Hay tanto sin hablar!).

O destinatario resultou ser José Alguero Penedo, bo amigo da Condesa, que ademais de notario era intelectual, escritor e artista; e como tal colaborou nalgúns deseños no Pazo de Meirás. Como notario e persoa de confianza de Pardo Bazán recibe ese documento confidencial que seguramente se corresponda co 
testamento hológrafo de dona Emilia, como xa o documentou o Grupo de Investigación La Tribuna no $\mathrm{n}^{\circ} 7$ da revista do mesmo nome.

É Alguero membro correspondente da Academia desde o momento da súa fundación, en 1905, once días máis tarde do nomeamento de Pardo Bazán como académica de honra.

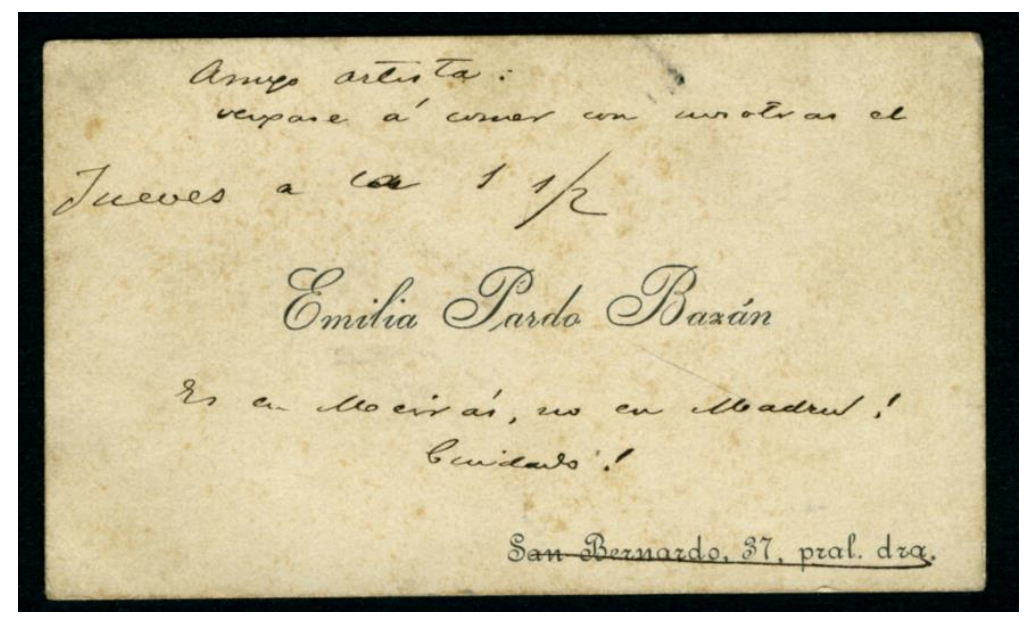

Invitación para José Alguero Penedo

As tarxetas tratan dous temas; sete delas falan de asuntos cotiáns: visitas, enfermidades, convites, novas de coñecidos, etc. O resto, trata sobre a decoración do Pazo de Meirás, na que Alguero participou activamente.

A dúas cartas falan da publicación de artigos de J. Alguero na prensa nacional e rexional, e de novo volven á decoración do pazo. Aquí dona Emilia ten moito acerto ao dicir:

Ya no llevará canecillos la fachada (resultaría demasiado alta) pero no se frote usted las manos: he de necesitar a V. para otros mil trabajos; para el decorado de la torre en construcción, que es la que yo he de habitar y quisiera imprimirle alguna huella personal, para cuando la visiten -si la visitan- los curiosos del año $2000 \ldots$

Acerta plenamente na curiosidade que nun futuro espertaría a súa persoa, mais quen lle diría as dificultades que habería para entrar no pazo...
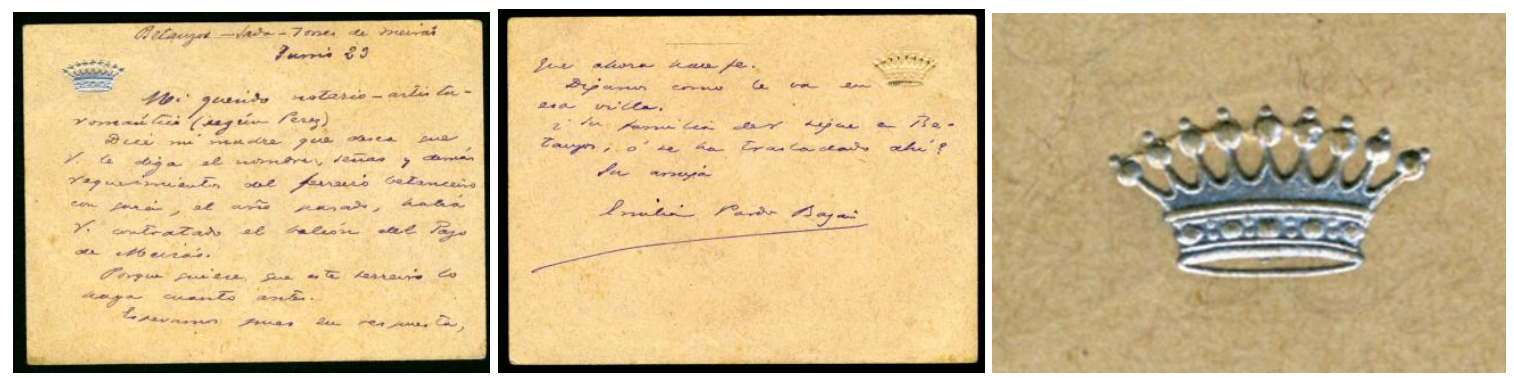

Tarxeta de Emilia Pardo Bazán a José Alguero e detalle da coroa

O segundo lote chega á Academia pola oferta directa dun vendedor, e está formado por:

Tres cartas $(1901,1910)$ entre Amalia de la Rúa, Condesa de Pardo Bazán -nai de Emilia-, e Ramón Platas, administrador das fincas de Vilasantar. Nelas a condesa viúva pide que a compraza nuns asuntos, e o administrador solicita á condesa que interceda a seu favor para a confirmación dun posto municipal. 
$\square \quad$ Tres cartas entre Emilia Pardo Bazán e Santiago de la Iglesia sobre unha publicación deste último, na que trata a figura de Concepción Arenal. 1907.

Unha tarxeta postal dirixida a Emilio M $^{\text {a }}$ de Torres. 1910.

Tamén Santiago de la Iglesia, nunha das súas cartas, se mostra visionario ao afirmar:

Porque estoy seguro de que dentro de un siglo, cuando hayamos desaparecido de la escena los actuales actores, el nombre de la Arenal y el de V. han de ser citados juntos cuando de enaltecer a Galicia se trate.

É esa admiración a que o levou a escribir sobre Concepción Arenal e os recordos que da súa nenez conservaba. E ao tempo, e tamén coa mesma admiración, deséxalle a dona Emilia unha longa vida.

Y hago estos votos porque el destino quiera retrasar muchos años la difícil tarea de escribir la biografía de V., de dibujar su figura y legarla a la posteridad fielmente...

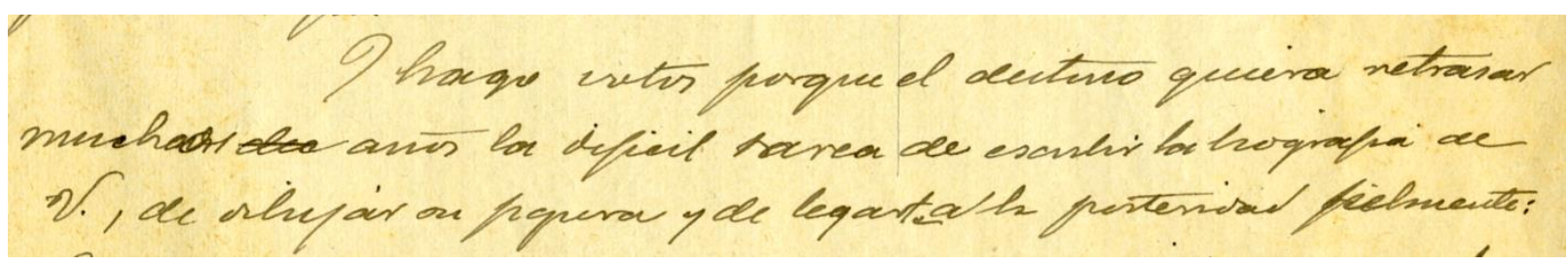




\section{BIBLIOGRAFÍA}

Iglesia, Santiago de la (1907): "Mis recuerdos de Concepción Arenal", en Mañach, Francisco, Concepción Arenal, la mujer más grande del siglo XIX, Buenos Aires

Grupo de investigación La Tribuna (2009): “La riqueza de Emilia Pardo Bazán. Una aproximación a su estudio", La Tribuna: Cadernos de Estudos da Casa-Museo Pardo Bazán, núm. 7, pp. 37-81

Núñez Varela y Lendoiro, José Raimundo ([xuño 2016]): El Autor de los Milagros de Nuestra Señora del Camino de Betanzos, www.cronistadebetanzos.com

Otero, Raúl ([xuño 2016]): El tiempo es un canalla,

$<$ http://eltiempoesuncanalla.blogspot.com.es/2015/03/jose-alguero-penedo.html> 